\title{
Differences of Spinal Curvature, Thoracic Mobility, and Respiratory Strength Between Chronic Neck Pain Patients and People Without Cervical Pain
}

\author{
Ji Hong Cheon, MD, Na Na Lim, MD, Geun Su Lee, MD, Ki Hong Won, MD, Sung Hoon Lee, MD, \\ Eun Young Kang, MD, Hyun Kyung Lee, MD, PhD, Younkyung Cho, MD
}

Department of Rehabilitation Medicine, Kwangju Christian Hospital, Gwangju, Korea

Objective To investigate the differences of spinal curvature, thoracic sagittal mobility, and respiratory strength between patients with chronic neck pain (CNP) and people without cervical pain, and to determine the correlation between respiratory strength and thoracic mobility in CNP patients.

Methods A total of 78 participants were finally included in this study, of whom 30 had no cervical pain and 48 had CNP. The Neck Disability Index (NDI), cervical lordotic curvature, thoracic kyphotic curvature, thoracic sagittal range of motion (ROM), maximal inspiratory pressure (MIP), and maximal expiratory pressure (MEP) were measured and analyzed.

Results In males, thoracic sagittal $\mathrm{ROM}_{\text {MEP-MIP }}$ and MEP showed a significant difference between the no cervical pain group and the CNP group. In females, thoracic kyphotic curvature, thoracic sagittal ROM $_{\text {MEP-MIP }}$ MIP, and MEP were significantly different between the no cervical pain group and the CNP group. Thoracic kyphotic curvature was significantly correlated with MEP and MIP in all population groups, and significantly correlated with NDI in the female group. Thoracic sagittal ROM $_{\text {MEP-MIP }}$ had a significant linear relationship with NDI, MEP, and MIP in all population groups.

Conclusion The thoracic mobility during forced respiration was reduced in patients with CNP and was correlated with respiratory strength. Changes in the biomechanics of the cervicothoracic spine and rib cage due to CNP may contribute to impairment of respiratory strength.

Keywords Neck pain, Respiratory function tests, Spinal curvatures

Department of Rehabilitation Medicine, Kwangju Christian Hospital, 37 Yangnim-ro, Nam-gu, Gwangju 61661, Korea. Tel: +82-62-650-5167, Fax: +8262-671-7447, E-mail: yhaehwan@daum.net

ORCID: Ji Hong Cheon (https://orcid.org/0000-0003-4366-1610); Na Na Lim (https://orcid.org/0000-0001-5743-9135); Geun Su Lee (https://orcid. org/0000-0003-2131-3148); Ki Hong Won (https://orcid.org/0000-0002-1456-7943); Sung Hoon Lee (https://orcid.org/0000-0002-2071-7936); Eun Young Kang (https://orcid.org/0000-0001-6805-5727); Hyun Kyung Lee (https://orcid.org/0000-0002-1464-2560); Younkyung Cho (https://orcid. org/0000-0003-4906-6089).

() This is an open-access article distributed under the terms of the Creative Commons Attribution Non-Commercial License (http://creativecommons.org/ licenses/by-nc/4.0) which permits unrestricted noncommercial use, distribution, and reproduction in any medium, provided the original work is properly cited. Copyright $\odot 2020$ by Korean Academy of Rehabilitation Medicine 


\section{INTRODUCTION}

Neck pain is the fourth leading cause of disability, with an annual prevalence rate of $>30 \%$ [1]. In addition to musculoskeletal pain, neck pain is also associated with dizziness, anxiety, and depression, and is known to cause disability in daily life [2]. Recently, some evidences showing that pulmonary function is reduced in patients with chronic neck pain (CNP) have been reported [3-6].

Vital capacity and functional vital capacity are significantly lower, and maximal voluntary ventilation is also lower, in CNP patients than in people without CNP $[3,4]$. It was revealed that respiratory muscle strength has a significant correlation with CNP [4-6]. Maximal expiratory pressure (MEP) and maximal inspiratory pressure (MIP) are also significantly associated with neck muscle strength and characteristics of CNP patients such as catastrophizing and kinesiophobia [5].

Although the thoracic spine is known to have a limited range of motion (ROM) owing to the robust rib cage, the sagittal posture of the thoracic spine and the thoracic mobility have a correlation with neck pain severity and disability [7-9]. There is a significant negative correlation between the thoracic curvature and lung function among older adults [10]. According to Lau et al. [8], thoracic flexion is significantly correlated with all neck motions, and there is a fair correlation between chest expansion and forward head posture.

Previous studies measured the spinal kyphotic curvature regardless of the respiratory status; however, the results may not represent the chest mobility and changes of spinal kyphotic curvature while breathing. Therefore, unlike previous studies, this study measured functional thoracic ROM associated with respiration, which means the thoracic sagittal ROM between MEP and MIP (thoracic sagittal $\mathrm{ROM}_{\text {MEP-MIP }}$ ) rather than maximum thoracic sagittal ROM, and attempted to determine the correlation between respiratory strength and functional spinal mobility in people without cervical pain and in CNP patients.

\section{MATERIALS AND METHODS}

\section{Subjects}

The study was conducted for 3 months, from October 2018 to December 2018, at the Department of Rehabilitation Medicine. Participants were recruited through leaf- lets and explanations in the physical therapy room and the outpatient clinic of the rehabilitation department. CNP patients were potentially included if they had posterior neck pain with or without headache and radiating pain for $\geq 6$ months and experienced the occurrence of pain at least once a week. Participants with no cervical pain were potentially included if they had no posterior neck pain or discomfort for $\geq 6$ months. All subjects were between 19 and 65 years old and were evaluated for the Neck Disability Index (NDI). To eliminate confounding factors, participants were excluded from this study if they had any of following conditions: (1) a history of surgery or trauma in the head, neck, upper trunk, and limbs; (2) systemic peripheral neuropathy; (3) myopathy; (4) congenital vertebral anomalies; (5) cardiopulmonary diseases including chronic obstructive pulmonary disease and asthma; (6) obesity (body mass index [BMI] $\geq 25 \mathrm{~kg} / \mathrm{m}^{2}$ ); (7) smoking habit for $>1$ year; (8) autoimmune diseases; and (9) abnormal findings on chest radiography. All procedures were approved by the Institutional Review Board of Kwangju Christian Hospital (No. M-2018-204), and written informed consent was obtained from the participants.

\section{Clinical assessments}

\section{Neck Disability Index}

The NDI is a 10-item questionnaire for assessing selfrated disability in patients with neck pain. The higher the score, the greater the severity of cervical dysfunction. It is the most widely used and most strongly validated instrument for assessing neck disability. In this study, the Korean version of the NDI, which was translated into Korean to reflect cultural differences and has shown high reliability (intraclass correlation coefficient $[$ ICC $]=0.927$, Cronbach's alpha $=0.82$ ), was used $[11,12]$.

\section{Musculoskeletal assessments \\ Radiographic cervical curvature}

Cervical curvature was assessed according to the Cobb angle C2-7 (angle between the horizontal line of the C2 lower endplate and the horizontal line of the $\mathrm{C} 7$ lower endplate) in the radiographic lateral view [13]. The subject was instructed to sit on a chair without a backrest and to look ahead as comfortably as possible. 
Thoracic kyphotic curvature measurement using flexicurve

Thoracic kyphotic curvature and thoracic sagittal $\mathrm{ROM}_{\text {MEP-MIP }}$ were measured using the flexicurve instrument. Flexicurve is a strip of flexible metal ruler covered in plastic that allows measuring the curvature of the spine. Teixeira and Carvalho [14] reported its intra-rater reliability (ICC $=0.87$ ) in a sample of 56 healthy participants with a mean age of 66 years. The interspinous space of L3-4 was identified at the level of the iliac crests, and the T12 spinous process was marked by palpating superiorly. The top of flexicurve was placed on the C7 spinous process, which is the most prominent spinous process, and was molded along the skin above the spine to the T12 spinous process [15]. After drawing the outline of the molded flexicurve, we measured the distance of the straight line $\left(\mathrm{X}=\mathrm{X}_{1}+\mathrm{X}_{2}\right)$ between $\mathrm{C} 7$ and $\mathrm{T} 12$ and measured the distance of the straight line (B) between $\mathrm{X}$ and the apex of kyphosis. Thereafter, the kyphotic angle was calculated using the following formula [16] (Fig. 1):

\section{Kyphotic angle $=\arctan \left(\mathrm{B} / \mathrm{X}_{1}\right)+\arctan \left(\mathrm{B} / \mathrm{X}_{2}\right)$.}

Thoracic kyphotic curvature was measured with the

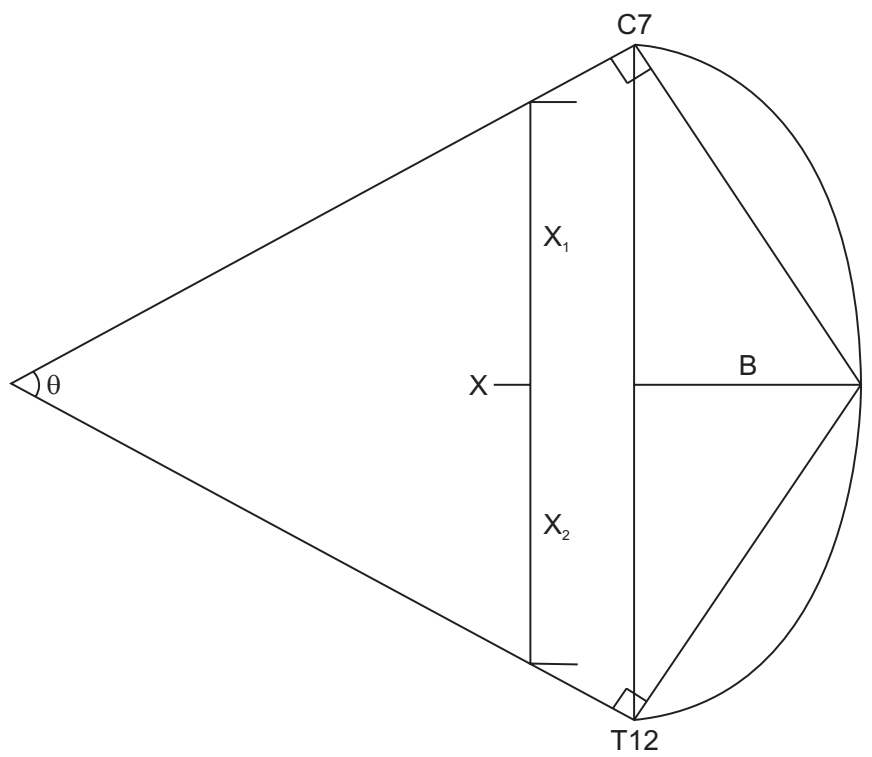

Fig. 1. Curves drawn through flexicurve and formula for calculating thoracic curvature. The straight line $(\mathrm{X})$ was measured between $\mathrm{C} 7$ and T12 and the straight line (B) was measured between $\mathrm{X}$ and apex of kyphosis. The kyphotic angle was calculated by the formula: $\arctan \left(\mathrm{B} / \mathrm{X}_{1}\right)$ $+\arctan \left(\mathrm{B} / \mathrm{X}_{2}\right)$. subject seated on the chair without a backrest and instructed to look ahead and breathe as usual.

Respiratory strength testing and thoracic sagittal $R O M_{M E P-M I P}$

To evaluate the strength of respiratory muscles, MIP and MEP were measured using a respiratory pressure meter (MicroRPM; Vyaire Medical Inc., Mettawa, IL, USA) that has shown good reliability in healthy people (ICC, 0.78-0.87 for MIP; ICC 0.82-0.90 for MEP) [17]. Generally, age-matched males present higher values than females owing to anatomical, structural, and hormonal differences, and age has a negative relationship to the strength of respiratory muscles $[18,19]$. Therefore, statistical analysis was separately performed according to sex. Thoracic sagittal $\mathrm{ROM}_{\text {MEP-MIP }}$ was measured in the following steps and was equal to the value of (ii) minus (i). (i) Thoracic kyphotic curvature was assessed during maximal inspiratory effort while the subject was holding the respiratory pressure meter, producing the MIP (Fig. 2A). (ii) Thoracic kyphotic curvature was assessed during maximal expiratory effort while the subject was holding the respiratory pressure meter, producing the MEP (Fig. 2B). The reliability of thoracic kyphotic curvature measurement by flexicurve was evaluated in the normal group by measuring again when $>95 \%$ of the maximum values of MIP and
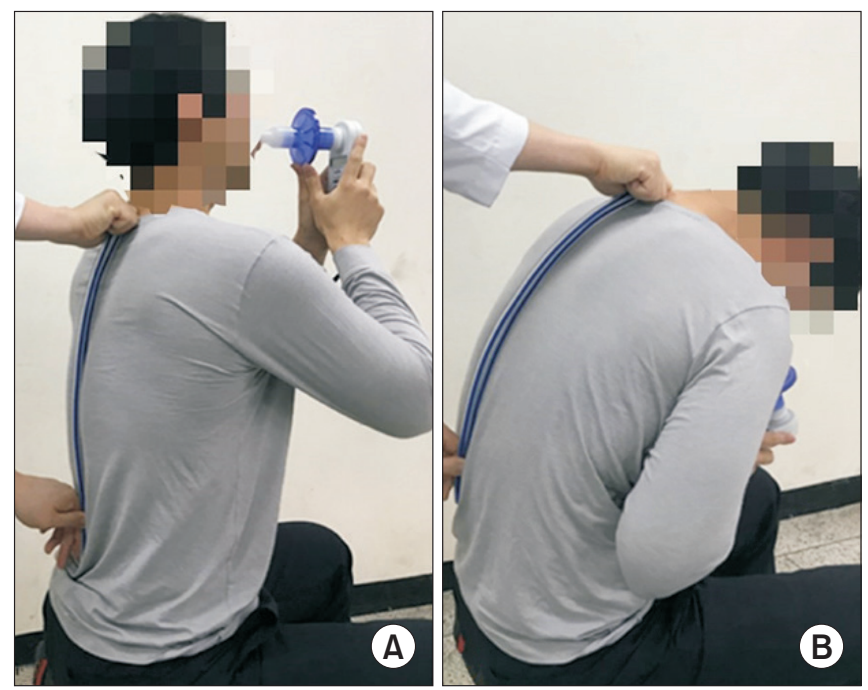

Fig. 2. Thoracic kyphotic curvature is measured by flexicurve. The subject is sitting on a chair without backrest. (A) Extending back while taking maximal inspiration to respiratory pressure meter. (B) Bending the trunk while taking maximal expiration to respiratory pressure meter. 
MEP were shown. The intra-rater reliability between the two trials was obtained (ICC $=0.72$ for MEP; ICC $=0.70$ for MIP; $\mathrm{p}<0.001)$.

\section{Statistical analysis}

Statistical analysis was performed using IBM SPSS statistics version 20.0 (IBM, Armonk, NY, USA). The study population consisted of three groups: (1) no cervical pain group (NDI $\leq 4)$, (2) mild disability group $(4<\mathrm{NDI} \leq 14)$, and (3) moderate to severe disability group $(14<\mathrm{NDI})$ [20]. The no cervical pain group and the CNP group were tested for normality using the Shapiro-Wilk test and compared using Student t-test. The no cervical pain group, mild CNP group, and moderate to severe CNP group were tested for normality using the Shapiro-Wilk test and compared using one-way analysis of variance followed by the Bonferroni test. For unequal variance, Welch t-test was performed. The correlations between variables were analyzed using Pearson correlation analysis. First, the linear relationships of cervical lordotic curvature, thoracic kyphotic curvature, and thoracic sagittal ROM $_{\text {MEP-MIP }}$ with NDI were analyzed. Additionally, the relationships of MEP and MIP to thoracic kyphotic curvature and thoracic sagittal $\mathrm{ROM}_{\text {MEP-MIP }}$ were analyzed using regression analysis.

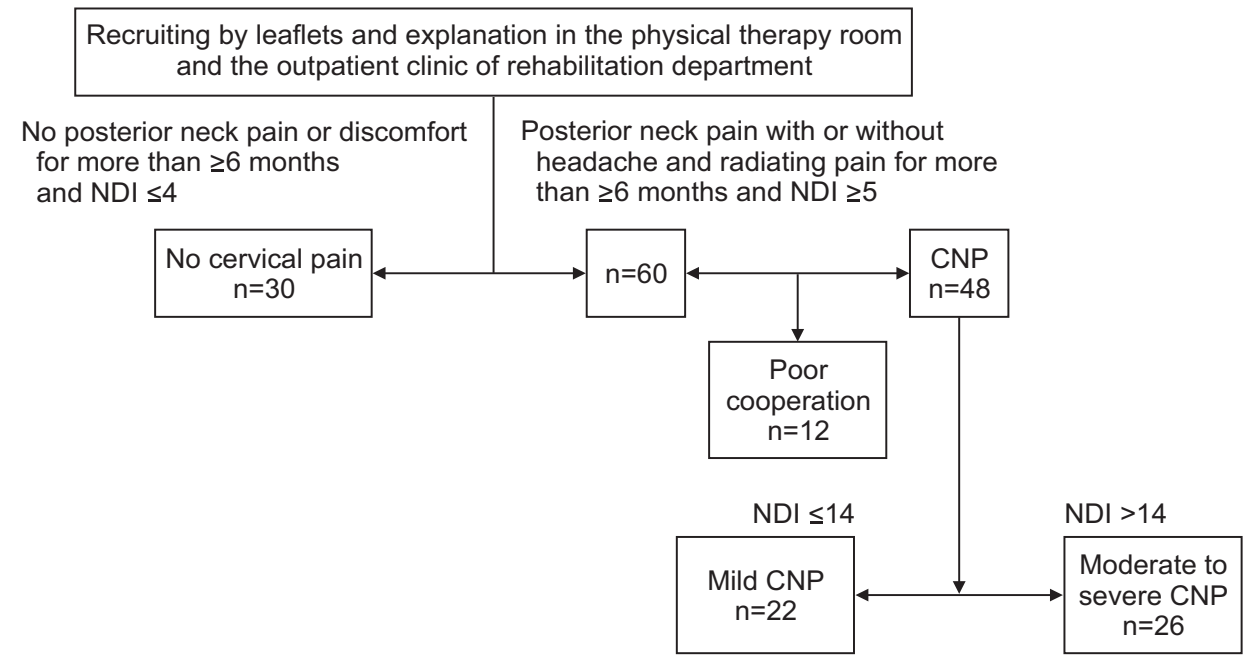

Fig. 3. Selection of study population. NDI, Neck Disability Index; CNP, chronic neck pain.

Table 1. Anthropometric and respiratory parameters in male and female

\begin{tabular}{lccc|}
\hline & All participants $(\mathbf{n}=\mathbf{7 8})$ & Male $(\mathbf{n}=\mathbf{3 8})$ & Female $(\mathbf{n}=\mathbf{4 0})$ \\
\hline Age $(\mathrm{yr})$ & $50.88 \pm 8.44$ & $49.84 \pm 8.49$ & $51.87 \pm 8.38$ \\
BMI $\left(\mathrm{kg} / \mathrm{m}^{2}\right)$ & $23.00 \pm 0.97$ & $22.96 \pm 0.99$ & $23.05 \pm 0.95$ \\
\hline NDI & $12.00 \pm 10.62$ & $12.15 \pm 10.62$ & $11.85 \pm 10.75$ \\
\hline Cervical lordotic curvature $\left(^{\circ}\right)$ & $11.76 \pm 3.50$ & $11.67 \pm 3.77$ & $11.85 \pm 3.27$ \\
\hline Thoracic kyphotic curvature $\left(^{\circ}\right)$ & $29.30 \pm 3.72$ & $28.76 \pm 3.57$ & $29.82 \pm 3.83$ \\
\hline Thoracic kyphotic curvature at maximal expiration $\left(^{\circ}\right)$ & $35.12 \pm 5.49$ & $37.86 \pm 5.07^{*}$ & $32.52 \pm 4.57^{*}$ \\
\hline Thoracic kyphotic curvature at maximal inspiration $\left(^{\circ}\right)$ & $20.11 \pm 3.36$ & $20.15 \pm 3.33$ & $20.07 \pm 3.44$ \\
\hline Thoracic sagittal $\operatorname{ROM}_{\text {MEP-MIP }}\left({ }^{\circ}\right)$ & $15.01 \pm 6.33$ & $17.71 \pm 6.34^{*}$ & $12.45 \pm 5.20^{*}$ \\
\hline MEP $\left(\mathrm{cmH}_{2} \mathrm{O}\right)$ & $109.08 \pm 16.30$ & $121.94 \pm 1.22^{*}$ & $96.87 \pm 10.56^{*}$ \\
\hline MIP $\left(\mathrm{cmH}_{2} \mathrm{O}\right)$ & $88.76 \pm 13.16$ & $98.05 \pm 9.94^{*}$ & $79.95 \pm 9.19^{*}$ \\
\hline
\end{tabular}

Values are presented as mean \pm standard deviation.

BMI, body mass index; NDI, Neck Disability Index; ROM $_{\text {MEP-MIP, }}$ range of motion between maximal expiration and inspiration; MEP, maximal expiratory pressure; MIP, maximal inspiratory pressure.

${ }^{*} \mathrm{p}<0.001$. 


\section{RESULTS}

There were 30 suitable participants who have had no posterior neck pain or no discomfort for $\geq 6$ months and had an NDI score of $\leq 4$, which indicates full recovery of pain-related disability [20]. Moreover, there were 60 potential participants who have had posterior neck pain with or without headache and radiating pain for $\geq 6$ months and experienced the occurrence of pain at least once a week and had an NDI score of $\geq 5$. For the potential CNP group, 12 participants were inadequate because they did not properly cooperate. The CNP group $(\mathrm{n}=48)$ was further classified into the mild group $(\mathrm{n}=22$, $4<\mathrm{NDI} \leq 14)$ and the moderate to severe group $(\mathrm{n}=26$, $14<\mathrm{NDI}$ ) according to the NDI score of 14 , which indicates moderate to severe levels of pain-related disability [20] (Fig. 3).

The participants had a mean age of $50.88 \pm 8.44$ years, with an average BMI of $23.00 \pm 0.97 \mathrm{~kg} / \mathrm{m}^{2}$, NDI of $12.00 \pm 10.62$, cervical lordotic curvature of $11.76^{\circ} \pm 3.50^{\circ}$, thoracic kyphotic curvature of $29.30^{\circ} \pm 3.72^{\circ}$, thoracic kyphotic curvature at maximal expiration of $35.12^{\circ} \pm 5.49^{\circ}$, thoracic kyphotic curvature at maximal inspiration of $20.11^{\circ} \pm 3.36^{\circ}$, thoracic sagittal $\mathrm{ROM}_{\text {MEP-MIP }}$ of $15.01^{\circ} \pm 6.33^{\circ}$, MEP of $109.08 \pm 16.30 \mathrm{cmH}_{2} \mathrm{O}$, and MIP of $88.76 \pm 13.16$ $\mathrm{cmH}_{2} \mathrm{O}$. The demographics presented significant differences with respect to thoracic sagittal $\mathrm{ROM}_{\text {MEP-MIP }}$ MIP, and MEP between men and women (Table 1). Therefore, statistical data were divided by sex.

In males, thoracic sagittal $\mathrm{ROM}_{\mathrm{MEP}-\mathrm{MIP}}$ and MEP showed a significant difference between the no cervical pain group and the CNP group. In females, thoracic kyphotic curvature, thoracic sagittal ROM $_{\text {MEP-MIP }}$ MIP, and MEP were significantly different between the CNP group and the no cervical pain group (Table 2).

Thoracic sagittal $\mathrm{ROM}_{\text {MEP-MIP }}$ was significantly different between the no cervical pain group and the mild group, and between the no cervical pain group and the moderate to severe group in males. Moreover, the mean difference in MEP between the no cervical pain group and the moderate to severe group was $10.47 \mathrm{cmH}_{2} \mathrm{O}(\mathrm{p}=0.021)$. In females, thoracic kyphotic curvature, thoracic sagittal ROM $_{\text {MEP-MIP }}$ MIP, and MEP were significantly different between the no cervical pain group and the moderate to severe group. Further, thoracic kyphotic curvature and thoracic sagittal $\mathrm{ROM}_{\text {MEP-MIP }}$ were significantly different

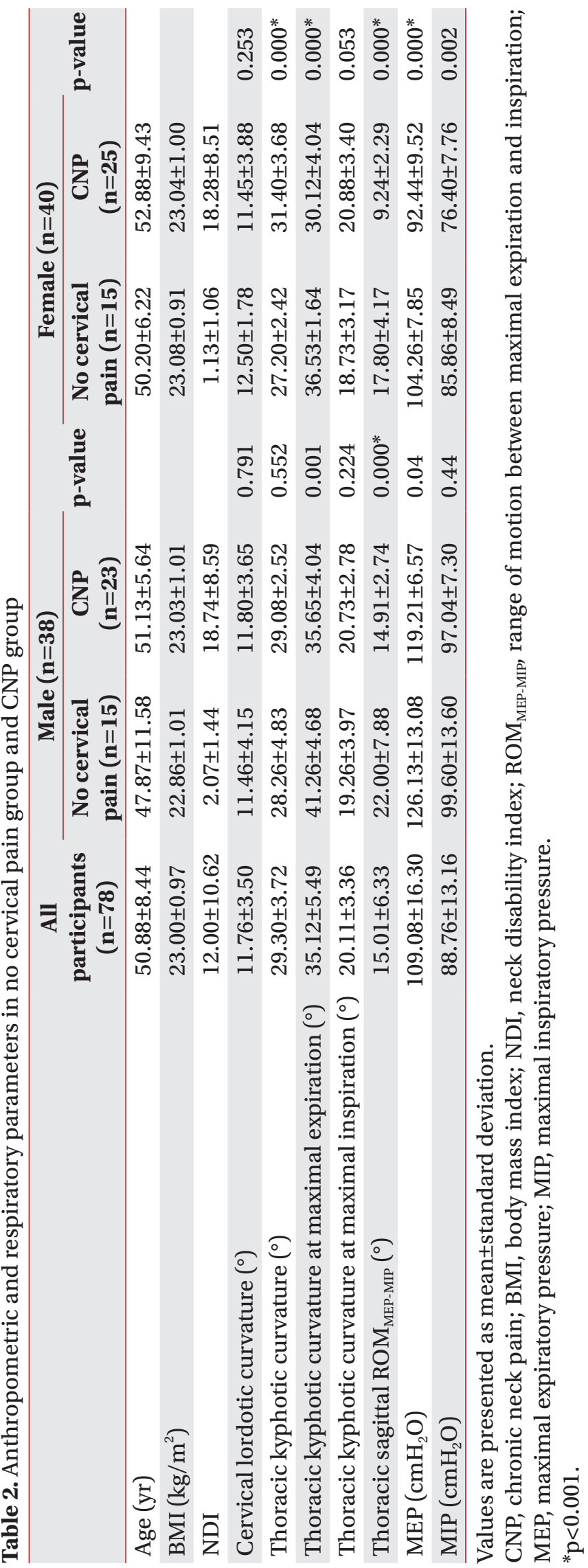




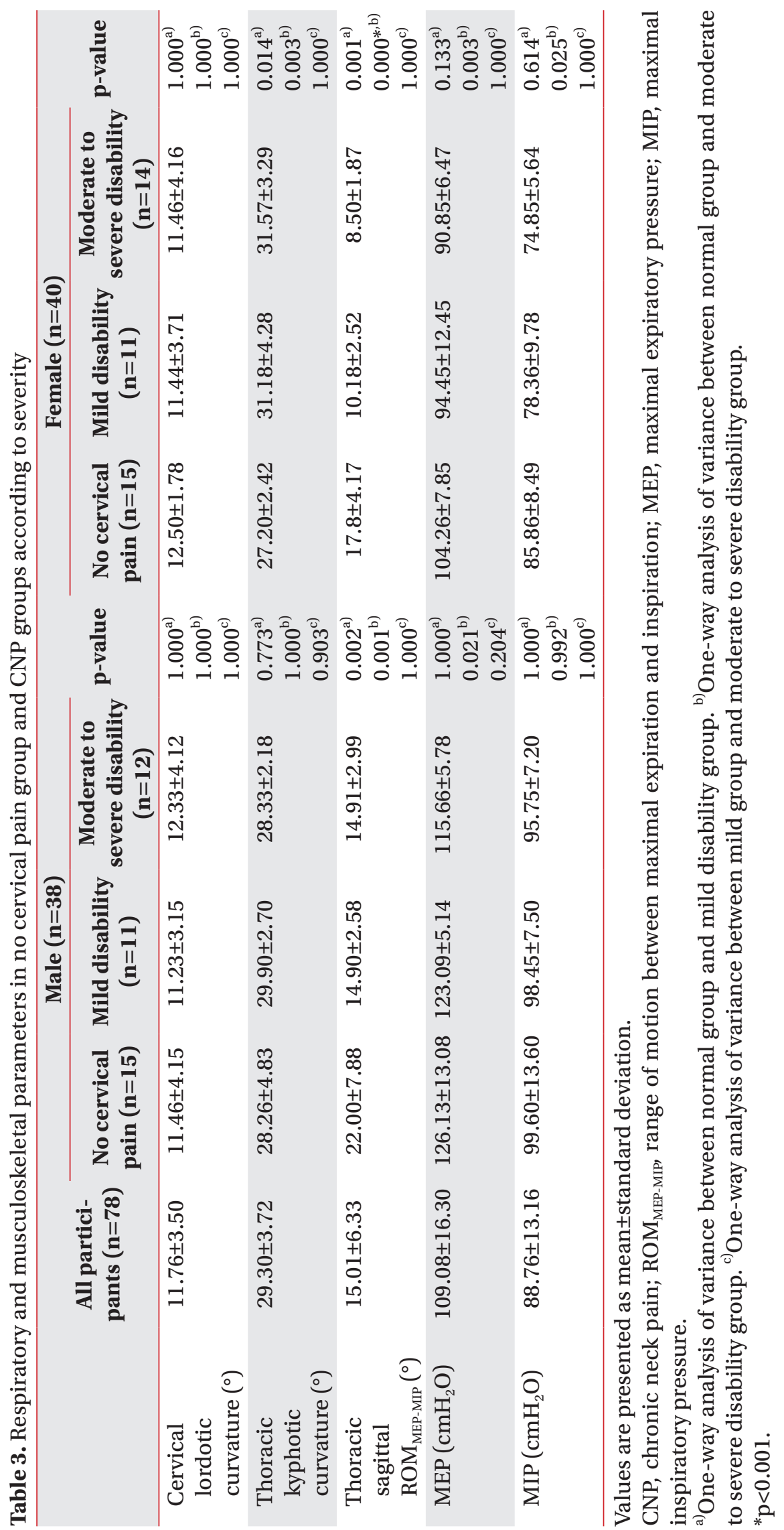



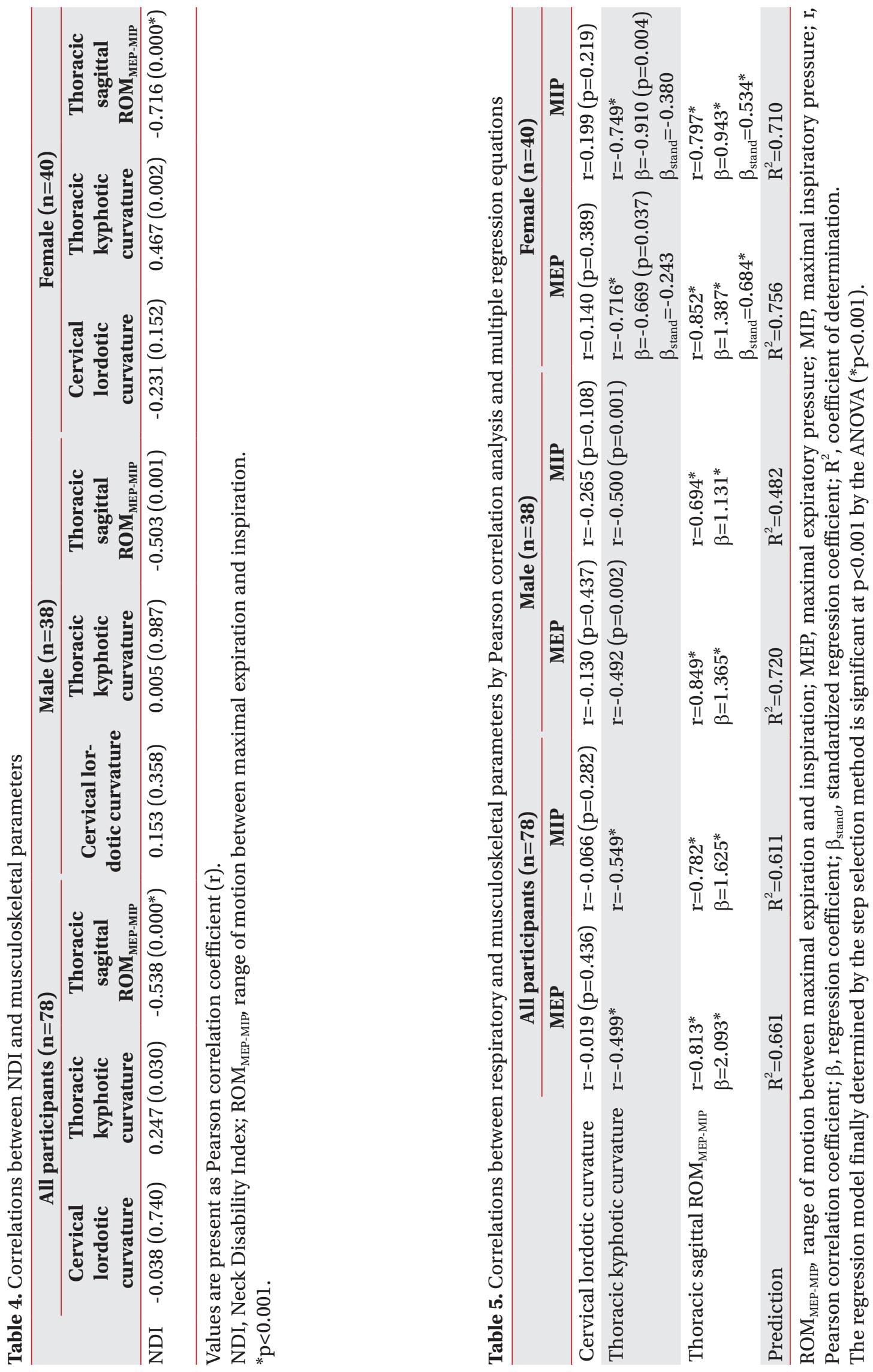
between the no cervical pain and the mild group (Table 3).

Thoracic kyphotic curvature was significantly correlated with NDI, MEP, and MIP in all participants. Similarly, thoracic sagittal $\mathrm{ROM}_{\text {MEP-MIP }}$ was also significantly correlated with NDI, MEP, and MIP in all participants (Tables 4, 5).

There was no significant linear relationship between NDI and cervical lordotic curvature. However, there was a significant linear relationship between NDI and thoracic kyphotic curvature in females, and there was a significant linear relationship between NDI and thoracic sagittal $\mathrm{ROM}_{\text {MEP-MIP }}$ in both males and females (Table 4).

Thoracic kyphotic curvature and thoracic sagittal $\mathrm{ROM}_{\text {MEP-MIP }}$ had a significant linear relationship with MEP and MIP in both sexes. According to multiple regression analysis, thoracic sagittal $\mathrm{ROM}_{\mathrm{MEP}-\mathrm{MIP}}$ was a more powerful factor with respect to MIP and MEP than thoracic kyphotic curvature (Table 5).

\section{DISCUSSION}

During respiratory movement, the lower rib moves like a bucket handle and the upper rib moves like a pump handle, whereas the rib angle can also change depending on the vertebral angle $[21,22]$. When thoracic extension occurs, the facet of the rib in the costotransverse joint undergoes inferior gliding and posterior rolling on the facet of the transverse process of the vertebra following the posterior rotation of the rib [23]. When the rib angle in the vertical plane is increased by decreasing the kyphotic vertebral segmental angle, the rib cage expands [21]. In contrast, when thoracic flexion occurs, the rib rotates anteriorly and chest contraction occurs [23]. In the high effort of inspiration, the diaphragm, external intercostalis, and sternomastoid act as actuators of the mobile rib cage and the external intercostalis accounts for a higher proportion of the respiratory force than the sternomastoid and diaphragm [21]. In high-effort expiration, the abdominal muscles act as actuators of the mobile rib cage and the distribution of expiratory strength is relatively even among the 4 abdominal muscles [21]. According to the length-tension relationship, to produce the MIP and MEP, isometric contraction of respiratory muscles is required and should occur at the optimal length of the muscles $[24,25]$. It is also necessary to maintain a specific angular position to generate the highest force for joint movement [26]. Therefore, it is hypothesized that the subject will take thoracic extension and flexion as optimal postures when MIP and MEP are produced, respectively. To the best of our knowledge, the thoracic mobility for maximal respiratory pressure was first measured in this study. Because ROM is a better concept than curvature for evaluating mobility, it was used for measuring mobility during maximal respiration, which was defined as the difference of the thoracic kyphotic curvature when the MIP and MEP were obtained. Thoracic flexion and extension were accomplished when the maximal respiratory pressures were obtained, and the mean value of the thoracic sagittal $\mathrm{ROM}_{\text {MEP-MIP }}$ was $19.90^{\circ}$ in the normal group in this study. Morita et al. [7] investigated thoracic sagittal ROM using computed tomography scanning and measurements of Cobb's angle of thoracic kyphosis. Although the thoracic spine is considered a stable region, the total thoracic sagittal ROM when the spine was fully flexed and extended was $31.7^{\circ}[7]$.

Respiration is a complex function involving the strict and absolute cooperation of the muscular, skeletal, and nervous systems [27]. In CNP patients, cervical instability, impairment of neck proprioception, neck muscle weakness, and imbalance affect the mobility and alignment of the thoracic spine and induce scapular dyskinesis [5,20,27-30]. Further, thoracic mobility can be impaired owing to avoidance behavior such as kinesiophobia, which is correlated with neck pain $[31,32]$. In terms of the force-length curve relationship, poor cervical muscle control and restricted cervical mobility result in adapted contraction patterns and mechanical adjustments of respiratory muscles $[24,27]$. Thereby, changes in the cervicothoracic local and global muscle systems affect the biomechanics of the rib cage and potentially change the respiratory function [5].

Body position influences the respiratory strength; however, the optimal position varies among studies. MIP is higher in the upright position than in the slouched position, and lower in the head-down-tilt position than in the standing, sitting, lying, and supine positions [32,33]. MIP and MEP are higher in the sitting position than in the supine and $45^{\circ}$ semi-upright positions [32]. Previous studies measured respiratory strength with the trunk fixed to a specific posture, which, in turn, limited the thoracic mobility and made the role of the diaphragm more prom- 
inent [33-35]. In this study, we measured posture when the respiratory strength was at the maximum, rather than measuring respiratory strength according to posture; thus, there is a limitation in comparing our results with those of previous studies.

The thoracic kyphotic curvature at MEP was $35.12^{\circ} \pm 5.49^{\circ}$ and the thoracic kyphotic curvature at MIP was $20.11^{\circ} \pm 3.36^{\circ}$. There was a significant difference in thoracic kyphotic curvature at MEP but not at MIP between the no cervical pain group and the CNP group in both sexes, which implies that the thoracic kyphotic curvature at MEP mainly contributes to the thoracic sagittal ROM $_{\text {MEP- }}$ MIP. We presumed that, for maximal action of the external intercostalis and abdominal muscles, which are the main actuators of high-effort inspiration and expiration, a high degree of trunk extension was not necessarily required by the external intercostalis, whereas a high degree of trunk flexion was demanded by the abdominal muscles [21].

It is known that the relationship between the mean value of the lordotic curve and the cervicogenic symptom is not consistent $[36,37]$. In a previous study, no association between the sagittal alignment of the cervical spine and neck pain was found, and there was no relationship between curvature and any index of cervical pain and disability in the group with neck pain [37]. In this study, cervical lordotic curvature was not significantly correlated with MIP, MEP, or NDI but thoracic sagittal ROM MEP- $_{\text {- }}$ мIP was significantly correlated (Tables 4,5 ). Because functional aspects of the cervical spine, such as ROM and strength, were not evaluated, only the thoracic spine seemed to be correlated with MIP, MEP, and NDI.

It was necessary to evaluate whether a subject would take the same posture when the same respiratory muscle strength is shown. In respiratory strength measurement, the slouched sitting position was reported to have a lower sniff nasal inspiratory pressure than the upright sitting position, with alteration of the body position reducing the diaphragm tension and movement [33]. Biomechanically, the strength that can be generated in a given motion depends on body posture (joint angles) and there are angular positions at which the maximal values of forces can be achieved for each joint movement [26]. This study assumed that the subject would take the same position (sitting upright on a chair without a backrest) when they show the same maximum forces. When the subjects became accustomed to measurement of MIP and MEP after several trials and were able to generate the maximum values of their MIP and MEP, the thoracic kyphotic curvature tended to be consistent. The thoracic kyphotic curvature measured using flexicurve had a moderate, but not excellent, reliability in this study, and its range was limited to the no cervical pain group.

Other methods can be used for measuring the thoracic kyphotic curvature, such as inclinometer or fluoroscopy measurements. We attempted to measure Cobb's angle with video fluoroscopy; however, unless the subjects were positioned exactly on the sagittal plane of the radiographic device, there were large errors in eliciting Cobb's angle. The use of an inclinometer for thoracic ROM measurement has been well studied. However, it was difficult to keep the inclinometer perpendicular to the surface of the spinous process and to keep the position constant while breathing. Furthermore, it takes a long time for the pointer to move and be stabilized by gravity. The angle measured by flexicurve is generally less than that measured by the inclinometer [16]. Therefore, there are limitations in comparing our results with those of other studies that measured the thoracic kyphotic curvature.

The definition of neck pain was ambiguous and dependent only on NDI, which assesses disability. The characteristic of neck pain was only described as posterior neck pain with or without headache and radiating pain. Therefore, this study was unable to distinguish the type of pain, such as radicular pain, myofascial pain, or facet pain.

In conclusion, the thoracic mobility during forced respiration was reduced in CNP patients and was correlated with respiratory strength. Changes in the biomechanics of the cervicothoracic spine and rib cage due to CNP may contribute to impairment of respiratory strength.

\section{CONFLICT OF INTEREST}

No potential conflict of interest relevant to this article was reported.

\section{AUTHOR CONTRIBUTION}

Conceptualization: Cheon JH, Cho Y. Methodology: Cheon JH, Lee SH, Kang EY, Cho Y. Formal analysis: Cheon JH, Lee SH. Project administration: Cho Y, Lee HK. Visualization: Lee GS, Won KH. Writing - original 
draft: Cheon JH. Writing - review and editing: Cheon JH, Cho Y. Approval of final manuscript: all authors.

\section{REFERENCES}

1. Cohen SP. Epidemiology, diagnosis, and treatment of neck pain. Mayo Clin Proc 2015;90:284-99.

2. Liu F, Fang T, Zhou F, Zhao M, Chen M, You J, et al. Association of depression/anxiety symptoms with neck pain: a systematic review and meta-analysis of literature in China. Pain Res Manag 2018;2018:3259431.

3. Dimitriadis Z, Kapreli E, Strimpakos N, Oldham J. Pulmonary function of patients with chronic neck pain: a spirometry study. Respir Care 2014;59:543-9.

4. Kapreli E, Vourazanis E, Billis E, Oldham JA, Strimpakos N. Respiratory dysfunction in chronic neck pain patients: a pilot study. Cephalalgia 2009;29:701-10.

5. Dimitriadis Z, Kapreli E, Strimpakos N, Oldham J. Respiratory weakness in patients with chronic neck pain. Man Ther 2013;18:248-53.

6. Wirth B, Amstalden M, Perk M, Boutellier U, Humphreys BK. Respiratory dysfunction in patients with chronic neck pain: influence of thoracic spine and chest mobility. Man Ther 2014;19:440-4.

7. Morita D, Yukawa Y, Nakashima H, Ito K, Yoshida G, Machino M, et al. Range of motion of thoracic spine in sagittal plane. Eur Spine J 2014;23:673-8.

8. Lau KT, Cheung KY, Chan KB, Chan MH, Lo KY, Chiu TT. Relationships between sagittal postures of thoracic and cervical spine, presence of neck pain, neck pain severity and disability. Man Ther 2010;15:457-62.

9. Ozer Kaya D, Toprak Celenay S. An investigation of sagittal thoracic spinal curvature and mobility in subjects with and without chronic neck pain: cutoff points and pain relationship. Turk J Med Sci 2017;47:891-6.

10. Rahman NN, Singh DK, Lee R. Correlation between thoracolumbar curvatures and respiratory function in older adults. Clin Interv Aging 2017;12:523-9.

11. Vernon H. The neck disability index: state-of-the-art, 1991-2008. J Manipulative Physiol Ther 2008;31:491502.

12. Song KJ, Choi BW, Choi BR, Seo GB. Cross-cultural adaptation and validation of the Korean version of the neck disability index. Spine (Phila Pa 1976) 2010;35:E1045-9.
13. Guo GM, Li J, Diao QX, Zhu TH, Song ZX, Guo YY, et al. Cervical lordosis in asymptomatic individuals: a meta-analysis. J Orthop Surg Res 2018;13:147.

14. Teixeira FA, Carvalho GA. Reliability and validity of thoracic kyphosis measurements using flexicurve method. Rev Bras Fisioter 2007;11:173-7.

15. Yanagawa TL, Maitland ME, Burgess K, Young L, Hanley D. Assessment of thoracic kyphosis using the flexicurve for individuals with osteoporosis. Hong Kong Physiother J 2000;18:53-7.

16. Greendale GA, Nili NS, Huang MH, Seeger L, Karlamangla AS. The reliability and validity of three nonradiological measures of thoracic kyphosis and their relations to the standing radiological Cobb angle. Osteoporos Int 2011;22:1897-905.

17. Dimitriadis Z, Kapreli E, Konstantinidou I, Oldham J, Strimpakos N. Test/retest reliability of maximum mouth pressure measurements with the MicroRPM in healthy volunteers. Respir Care 2011;56:776-82.

18. Gil Obando LM, Lopez Lopez A, Avila CL. Normal values of the maximal respiratory pressures in healthy people older than 20 years old in the City of Manizales - Colombia. Colomb Med (Cali) 2012;43:119-25.

19. Neder JA, Andreoni S, Lerario MC, Nery LE. Reference values for lung function tests. II. Maximal respiratory pressures and voluntary ventilation. Braz J Med Biol Res 1999;32:719-27.

20. Ritchie C, Hendrikz J, Kenardy J, Sterling M. Derivation of a clinical prediction rule to identify both chronic moderate/severe disability and full recovery following whiplash injury. Pain 2013;154:2198-206.

21. Ratnovsky A, Elad D. Anatomical model of the human trunk for analysis of respiratory muscles mechanics. Respir Physiol Neurobiol 2005;148:245-62.

22. Perri MA, Halford E. Pain and faulty breathing: a pilot study. J Bodyw Mov Ther 2004;8:297-306.

23. Lee DG. Biomechanics of the thorax - research evidence and clinical expertise. J Man Manip Ther 2015; 23:128-38.

24. Gordon AM, Huxley AF, Julian FJ. The variation in isometric tension with sarcomere length in vertebrate muscle fibres. J Physiol 1966;184:170-92.

25. Zhang G, Chen X, Ohgi J, Jiang F, Sugiura S, Hisada T. Effect of intercostal muscle contraction on rib motion in humans studied by finite element analysis. J Appl Physiol (1985) 2018;125:1165-70. 
26. Komi P. Strength and power in sport. 2nd ed. Chichester: John Wiley \& Sons; 2003.

27. Kapreli E, Vourazanis E, Strimpakos N. Neck pain causes respiratory dysfunction. Med Hypotheses 2008;70:1009-13.

28. Jull G, Barrett C, Magee R, Ho P. Further clinical clarification of the muscle dysfunction in cervical headache. Cephalalgia 1999;19:179-85.

29. Watson DH, Trott PH. Cervical headache: an investigation of natural head posture and upper cervical flexor muscle performance. Cephalalgia 1993;13:27284.

30. Castelein B, Cools A, Parlevliet T, Cagnie B. Are chronic neck pain, scapular dyskinesis and altered scapulothoracic muscle activity interrelated? A case-control study with surface and fine-wire EMG. J Electromyogr Kinesiol 2016;31:136-43.

31. Luque-Suarez A, Martinez-Calderon J, Falla D. Role of kinesiophobia on pain, disability and quality of life in people suffering from chronic musculoskeletal pain: a systematic review. Br J Sports Med 2019;53:554-9.

32. Leeuw M, Goossens ME, Linton SJ, Crombez G, Boers- ma K, Vlaeyen JW. The fear-avoidance model of musculoskeletal pain: current state of scientific evidence. J Behav Med 2007;30:77-94.

33. Albarrati A, Zafar H, Alghadir AH, Anwer S. Effect of upright and slouched sitting postures on the respiratory muscle strength in healthy young males. Biomed Res Int 2018;2018:3058970.

34. Costa R, Almeida N, Ribeiro F. Body position influences the maximum inspiratory and expiratory mouth pressures of young healthy subjects. Physiotherapy 2015;101:239-41.

35. Segizbaeva MO, Pogodin MA, Aleksandrova NP. Effects of body positions on respiratory muscle activation during maximal inspiratory maneuvers. Adv Exp Med Biol 2013;756:355-63.

36. McAviney J, Schulz D, Bock R, Harrison DE, Holland B. Determining the relationship between cervical lordosis and neck complaints. J Manipulative Physiol Ther 2005;28:187-93.

37. Grob D, Frauenfelder H, Mannion AF. The association between cervical spine curvature and neck pain. Eur Spine J 2007;16:669-78. 